\title{
Re: Electroconvulsive therapy during pregnancy revisited
}

\author{
Kari Ann Leiknes ${ }^{1}$
}

Published online: 5 June 2015

(C) Springer-Verlag Wien 2015

Our extended thanks to Donna Stewart for her comments (Stewart 2015) on our case report review about the use of electroconvulsive therapy during pregnancy (Leiknes et al. 2013). We understand the "limits of knowledge" based on earlier reviews influencing the 2001 text book (Stewart and Erlick Robinson 2001). We are sorry to hear that this important book on the interface between psychiatry and gynecology will not be updated into a later revised version. Stewart's article on ECT treatment during pregnancy, with case vignette (Stewart 2011), express a reservation for ECT during pregnancy, alongside an awareness for careful ECT monitoring. This case vignette was not included in our review due to insufficient primary data.

We are glad to hear Donna Stewart's position on not to recommend ECT during pregnancy as a first-line treatment and without appropriate safeguards. We totally agree that existing guidelines need to be revised and systematic reviews revised, when appropriate, on this topic. Future growth in published reports, register data, and studies on the administration of ECT during pregnancy will no doubt add more body to our knowledge on both benefits and harms of the intervention.
This again will be an aid to inform clinicians and women in complicated treatment decision making. Until then, bearing in mind potential harms as mentioned in our review, ECT during pregnancy will require a close monitoring of the fetus/baby and mother in a joint specialist treatment collaboration, between obstetrician and psychiatrist.

\section{References}

Leiknes KA, Cooke MJ, Jarosch-von Schweder L, Harboe I, Hoie B (2013) Electroconvulsive therapy during pregnancy: a systematic review of case studies. Arch Womens Ment Health. doi:10.1007/ s00737-013-0389-0

Stewart DE (2011) Clinical practice. Depression during pregnancy. N Engl J Med 365(17):1605-1611. doi:10.1056/NEJMcp1102730

Stewart D (2015) Electroconvulsive therapy during pregnancy revisited. Arch Womens Ment Health 1-2. doi:10.1007/s00737-015-0517-0

Stewart DE, Erlick Robinson G (2001) Psychotropic drugs and electroconvulsive therapy during pregnancy and lactation. In: Stotland NL, Stewart DE (eds) Psychological aspects of women's health care: the interface between psychiatry and obstetrics and gynecology xviii, 2nd edn. American Psychiatric Press Inc, Washington, DC, pp 6793, 654 pp
Kari Ann Leiknes

Kari.Ann.Leiknes@kunnskapssenteret.no

1 Department of Systematic Reviews, Norwegian Knowledge Centre for the Health Services, BOX 7004, St. Olavsplass,

0130 Oslo, Norway 